ORIGINAL ARTICLE

\title{
Limb Salvage in Early Versus Delayed Revascularization of Acute Lower Limb Ischemia
}

SALMAN JAMIL NOOR ${ }^{1}$, NAUMAN IMTIAZ ${ }^{2}$, WISHAL SHAUKAT ${ }^{3}$, ATHAR ABBAS GILANI ${ }^{4}$, PALWASHA SHAHID ${ }^{5}$, TAUQEER ALAM ${ }^{6}$, SYED MUNIM HUSSAIN ${ }^{7}$

${ }^{1}$ Thoracic \& General Surgeon, CMH Peshawar

${ }^{2}$ Head of Department of Vascular Surgery, CMH Peshawar

${ }^{3}$ Resident General Surgeon, CMH Peshawar

${ }^{4}$ General Surgeon, CMH Peshawar

${ }^{5}$ Resident Gynecology \& Obstetrics, FFH Rawalpindi

${ }^{6}$ Resident General Surgeon, CMH Peshawar

${ }^{7}$ Medical Officer, RMU, Rawalpindi

Correspondence to Lt. Col. Salman Jamil Noor, E-mail: salman_jamil786@hotmail.com Cell: 0300-5014320

\begin{abstract}
Aim: To compare the limb salvage rate in early versus late presenting patients of Rutherford class IIB acute lower extremity ischemia undergoing revascularization.

Study Design: Comparative/observational study

Place and duration of study: Department of Surgery, CMH Peshawar from January 2019 to March 2021

Methodology: Twenty eight patients of both genders with ages 20 to 70 years presented with Rutherford class IIB acute lower limb ischemia were enrolled in this study. Patients were divided into two groups. Group I (presented after 6 hours of onset of symptoms) consisted of 20 patients and group II (presented within 6 hours of onset of symptoms) consisted of 8 patients. All the patients underwent femoral embolectomy. Limb salvage rate between both groups was examined at postoperative $3^{\text {rd }}$ month. Data was analyzed by SPSS 24.0 . P-value $<0.05$ was taken as significant.

Results: There were $16(80 \%)$ male and $4(20 \%)$ females with mean age $50.52 \pm 11.74$ years in group I, in group II $6(75 \%)$ were male and $2(25 \%)$ were females with mean age $50.08 \pm 10.94$ years. No significant difference was observed between both groups regarding age and gender with $p$-value $>0.05$. In group I, limb salvage found in $19(95 \%)$ patients while in group II limb salvage found in $5(62.5 \%)$ patients, a significant difference was observed regarding limb salvage rate between both groups $(p$-value $<0.05)$. Mortality rate was high in group II (delayed presentation) as compared to group I $(12.5 \%$ Vs $0 \%)$ with p-value $<0.05$.

Conclusion: The limb salvage rate was high in early presenting patients than late presenting patients with a significant difference. 30 days mortality rate and amputation rate were significantly high in delayed presentation as compared to early presented cases.
\end{abstract}

Keywords: Acute lower limb ischemia, revascularization, limb salvage

\section{INTRODUCTION}

A sudden decline in blood flow to a limb is known as Acute Limb Ischemia (ALI), a possible threat to the viability of the limbs ${ }^{1}$. ALI is a medical emergency that is particularly morbid and dangerous, while thrombolytic, endovascular or free vascular surgery is urgently revascularization the rates of 30 days of amputation and mortality vary from $10 \%$ to $5 \%$ and $5 \%$ to $15 \%$ respectively 2,3 . The related morbidity and death is exceptionally high, with an average mortality rate of $40 \%$ in the USA ${ }^{4}$. This disease is affecting 15-26 people every 100.000 a year.

Systemic anticoagulation and early effective therapy have been used for acute limb ischemia. Class I acute limb ischemia (ALI) of Rutherford is generally treated only with anticoagulation, while category III of Rutherford typically calls for amputational procedures. Revascularization of patients with Rutherford Class II ALI is mostly required. In developed countries, however, the majority of the patients arrive late because of the uncertainty in their diagnosis. ${ }^{6,7}$ We conducted present study to examine the limb salvage rate in patients presented late and compare with early presented patients whom were undergoing

Received on 13-04-2021

Accepted on 27-08-2021 revascularization for Rutherford class IIB acute lower limb ischemia.

The objective of the study was to compare the limb salvage rate in early versus late presenting patients of Rutherford class IIB acute lower extremity ischemia undergoing revascularization.

\section{MATERIALS AND METHODS}

This comparative/observational study was conducted at Department of Surgery, CMH Peshawar from 1 January 2019 to 1 March 2021 after approval from IRB. A total of 28 patients of both genders with ages 20 to 70 years presented with Rutherford class IIB acute lower limb ischemia were enrolled in this study. All the patients were divided in to two groups, group I consist of 20 patients who presented early( $\leq 6$ hours) and group II had 8 patients whom presented late ( $>6$ hours). Patients detailed demographics including age, sex, body mass index, and co-morbidities were recorded after taking written consent from all the patients. Patients with history of vascular surgery, Rutherford class I, IIA and III, and patients with traumatic acute limb ischemia were excluded from this study. 
Femoral Embolectomy was performed in all the cases under local anaesthesia. Fasciotomy was performed in majority of patients in delayed presentation group and no fasciotomy was done in early presentation group. The patients were carefully examined in the ICU within 6 hours after surgery and then every 12 hours. Detailed clinical examination included examination of distal pulses and hand held Doppler examination in case pulses were not palpable. Postoperatively heparin infusion (80 IU/Kg/hr) was continuously administered. Tab Rivaroxaban $20 \mathrm{mg}$ at bed time was started on second postoperative day. Heparin infusion was stopped on morning of $4^{\text {th }}$ postoperative day. Regular monitoring of heparin anticoagulation was done by 12 hourly PTTK. Patients without fasciotomy were discharged on $5^{\text {th }}$ postoperative day while patients with fasciotomy were discharged between postoperative day 7 and 14. Fasciotomy was closed when swelling settled. Patients were followed up weekly for one month and fortnightly for another 1 months. Limb salvage rate was recorded at 2 months after surgery. All the data was analyzed by SPSS 24.0. P-value $<0.05$ was taken as statistically significant.

\section{RESULTS}

There were $16(80 \%)$ male and $4(20 \%)$ females with mean age $50.52 \pm 11.74$ years in group I, in group II 6(75\%) were male and 2(25\%) were females with mean age $50.08 \pm 10.94$ years. No significant difference was observed in age and gender between the groups $(P>0.05)$. Also no significant difference was found regarding $\mathrm{BMl}$ between both groups I and II $\left(26.26 \pm 3.82 \mathrm{~kg} / \mathrm{m}^{2}\right.$ Vs $\left.25.92 \pm 3.24 \mathrm{~kg} / \mathrm{m}^{2}\right)$ with $p$-value $>0.05$. No significant difference was observed regarding co-morbidities between both groups ( $p$-value $>0.05$ ). Comorbidities and associated risk factors are shown in Table 1.

Superficial femoral artery was most commonly affected vessel in group I while popliteal artery was most commonly affected in group II (Table 2).

Mean hospital stay in group I was $5.45 \pm 1.8$ days and in group I it was $10.76 \pm 3.56$ days, the difference was statistically significant $(P=0.002)$. Major amputation rate within 60 days was high in group II, $3(37.5 \%)$ patients as compared to group I 1 (5\%) (Table 3).

Table 1: Co-morbidities and risk factors
\begin{tabular}{|l|c|c|c|}
\hline \multicolumn{1}{|c|}{ Variable } & Group I (Early) & Group II (Late) & Total \\
\hline Diabetes Mellitus & $3(15 \%)$ & $2(25 \%)$ & 5 \\
\hline Smoking & $5(25 \%)$ & $3(37.5 \%)$ & 8 \\
\hline Hypertension & $9(45 \%)$ & $4(50 \%)$ & 13 \\
\hline Obesity & $2(10 \%)$ & $1(12.5 \%)$ & 3 \\
\hline Ischemic heart disease & $3(15 \%)$ & $2(25 \%)$ & 5 \\
\hline Atrial fibrillation & $4(20 \%)$ & $1(12.5 \%)$ & 5 \\
\hline
\end{tabular}

Table 2: Arteries affected

\begin{tabular}{|l|c|c|}
\hline Variables & Group I (Early) & Group II (Late) \\
\hline Ext iliac artery & $1(5 \%)$ & - \\
\hline Common femoral artery & $5(25 \%)$ & $2(25 \%)$ \\
\hline Superficial femoral artery & $6(30 \%)$ & $1(12.5 \%)$ \\
\hline Popliteal artery & $5(25 \%)$ & $4(50 \%)$ \\
\hline AT/PT artery & $3(15 \%)$ & $1(12.5 \%)$ \\
\hline
\end{tabular}

Table 3: Hospital stay and amputation rate between both groups

\begin{tabular}{|l|c|c|c|}
\hline Variables & Group I (Early) & Group II (Late) & P-value \\
\hline Hospital stay & $10.76 \pm 3.56$ & $5.45 \pm 1.8$ & 0.002 \\
\hline Amputation & $1(5 \%)$ & $3(37.5 \%)$ & 0.024 \\
\hline
\end{tabular}

\section{DISCUSSION}

Acute lower limb ischemia is one of the commonest vascular emergency encountered all over the world and associated with higher morbidity and mortality rate. Early presentation and accurate diagnosis can reduce the complications and mortality associated with $\mathrm{ALI}^{8}$. Revascularization is considered a treatment of choice for the management of acute lower extremity ischemia due to its higher limb salvage rate and fewer rate of complications. ${ }^{9}$ Majority of patients in the present study were males $78.57 \%$ as compared to females $21.42 \%$. These results are similarity to the previous studies in which male predominance of $65 \%$ to $75 \%$ was seen ${ }^{10,11}$.

We found that the mean age of patients in late group was $50.52 \pm 11.74$ years and in early group, it was $50.08 \pm 10.94$ years. No significant difference $(P<0.05)$ was observed between both groups regarding age and gender. Also no significant difference $(P>0.05)$ was found regarding BMI between both groups I and II $\left(26.26 \pm 3.82 \mathrm{~kg} / \mathrm{m}^{2} \mathrm{Vs}\right.$ $\left.25.92 \pm 3.24 \mathrm{~kg} / \mathrm{m}^{2}\right)$. These results were comparable to the study by Chaudhari et al ${ }^{12}$.

In the our study, hypertension was the commonest co-morbid condition in both early and late presented patients followed by smoking, diabetes, ischemic heart disease and arterial fibrillation. In a study conducted by Baril et $\mathrm{al}^{13}$ regarding outcomes of lower extremity bypass for acute lower limb ischemia, diabetes mellitus was the most frequent comorbidity found in ALI patients followed by hypertension and smoking.

In present study, hospital stay was longer in late presenting patients $(10.76 \pm 3.56$ days)as compared to early presenting patients(5.45 \pm 1.8$)$. The difference was statistically significant. Previous studies demonstrated that patients who presented late for revascularization for acute limb ischemia had longer hospital stay (above 10 days) as compared to patients presented early (mean 5 days). ${ }^{14,15}$ We found that 30 days amputation rate was high in late presented patients as compared to early presented patients $(37.5 \%$ Vs $5 \%$ ). The difference was statistically significant. Rothenburg et al $^{16}$ reported in their study that delayed fasciotomy is highly associated with major amputation in patients with acute lower extremity ischemia as compared to early fasciotomy $50 \%$ Vs $5.9 \%$.

In our study, limb salvage was found in 19 (95\%) patients in group I while in group II limb salvage was found in $5(62.5 \%)$ patients. A significant $(P<0.05)$ difference was observed regarding limb salvage rate between both groups. Chaudhary et $\mathrm{al}^{12}$ reported that the limb salvage rate was $91.67 \%$ in the early presenting group, whereas in the delayed presenting group, it was $72.73 \%$. No significant difference was observed regarding limb salvage rate between early and late presenting patients of acute lower limb ischemia.In a study by Sidique et $\mathrm{al}^{17}$ to examine the outcome of embolectomy in late presenting patients of acute lower limb ischemia, limb salvage rate was $85.7 \%$.

In current study, mortality rate was high in group II as compared to group I (12.5\% vs $0 \%)$ with p-value $<0.05$. A study conducted by Kempe et al $^{18}$ included 170 acute lower extremity ischemia patients with majority (83\%) presenting beyond 6 hours. They reported $85 \%$ limb salvage rate at 3 months. In their study, $52 \%$ of the patients were in 
Rutherford Class IIB. The median time to amputation was 1 day and the 30-day mortality was $18 \%$. Another study conducted by Khan et $\mathrm{al}^{6}$ reported that patients who presented after 72 hours for revascularization for ALI the limb salvage rate was $80 \%$ and mortality was $5 \%$. Some other previous studies demonstrated that patients who presented late (more than 72 hours to 15 days) had higher mortality rate as compared to early presenting patients ${ }^{19,20}$.

\section{CONCLUSION}

Revascularization for acute lower limb ischemia showed better outcomes in early presenting patients as compared to late presenting patients. Limb salvage rate was high in early presenting patients than late presenting one and the difference was statistically significant. Moreover, hospital stay, 30 day mortality and amputation rate was significantly high in late presenting patients.

Conflict of interest: Nil

\section{REFERENCES}

1. Wang SK, Murphy MP, Gutwein AR, Drucker NA, Dalsing $\mathrm{MC}$, Motaganahalli RL, et al. Perioperative outcomes are adversely affected by poor pretransfer adherence to acute limb ischemia practice guidelines. Ann Vasc Surg 2018;50:46-51.

2. Kuukasjärvi $P$, Salenius JP. Perioperative outcome of acute lower limb ischaemia on the basis of the national vascular registry. Finnvasc Study Group.Eur J Vasc Surg1994;8:57883.

3. Creager MA, Conte JA. Acute limb ischemia. N Engl J Med 2012; 366: 2198-2206.

4. Norgren L, Hiatt WR, Dormandy JA, Nehler MR, Harris KA, Fowkes FGR. Inter-society consensus for the management of peripheral arterial disease (TASC II). J Vasc Surg2007;45:S567.

5. Gerhard-Herman MD, Gornik HL, Barrett C, Barshes NR, Corriere MA, Drachman DE,et al. 2016 AHA/ACC Guideline on the management of patients with lower extremity peripheral artery disease: executive summary: a report of the American College of Cardiology/American Heart Association Task Force on Clinical Practice Guidelines. J Am Coll Cardiol2017;69:1465-508.

6. Khan MI, Nadeem IA. Revascularization of late - presenting acute limb ischaemia and limb salvage. J Ayub Med Coll Abbottabad 2016;28:262-6.

7. Nagarsheth $\mathrm{KH}$, Nassiri N, Shafritz R, Rahimi S. Delayed revascularization for acute lower extremity ischemia leads to increased mortality. J Vasc Surg 2016;63:121S-2.
8. von Keudell AG, Weaver MJ, Appleton PT, et al. Diagnosis and treatment of acute extremity compartment syndrome. Lancet 2015; 386: 1299-1310

9. Miyake K, Kikuchi S, Kitani Y, Koya A, Takeuchi T, Hasebe N, et al. Successful simultaneous revascularization for acute limb ischemia and concomitant acute myocardial infarction. Ann Vasc Dis2018;11(3):361-4.

10. Duff S, Mafilios MS, Bhounsule P, Hasegawa JT. The burden of critical limb ischemia: a review of recent literature.Vasc Health Risk Manag 2019;15:187-208

11. Mustapha JA, Katzen BT, Neville RF, Lookstein Ra, Zeller T, Miller LE, et al. Determinants of long-term outcomes and costs in the management of critical limb ischemia: a population-based cohort study.J Am Heart Assoc 2018;7(16):e009724.

12. Chaudhari HK, Vivekanand, Motukuru V, Sumanthraj KB, Rodney SR, Vishal H. A comparative study of postrevascularization limb salvage rate in early versus delayed presentation of Rutherford class IIB acute lower extremity ischemia. Indian J Vasc Endovasc Surg 2020;7:58-62.

13. Baril DT, Patel VI, Judelson DR, Goodney PP, McPhee JT, Hevelone ND, et al. Outcomes of lower extremity bypass performed for acute limb ischemia.J Vasc Surg2013;58(4):949-56.

14. Agarwal S, Sud $\mathrm{K}$, Shishehbor $\mathrm{MH}$. Nationwide trends of hospital admission and outcomes among critical limb ischemia patients: from 2003-2011.J Am Coll Cardiol 2016;67(16):1901-13.

15. Malyar NM, Freisinger E, Meyborg M, Luders F, Furstenberg $\mathrm{T}$, Kroger $\mathrm{K}$, et al. Low rates of revascularization and high inhospital mortality in patients with ischemic lower limb amputation: morbidity and mortality of ischemic amputation.Angiology 2016;67(9):860-9.

16. Rothenberg KA, George EL, Trickey AW, Chandra V, Stern JR. Delayed fasciotomy is associated with higher risk of major amputation in patients with acute limb ischemia.Ann Vasc Surg2019;59:195-201.

17. Siddique A, Imtiaz N, Pervaiz, Ali K, Ahmad R, Haider F. Outcome of embolectomy in patients presenting late with acute limb ischemia. J Ayub Med Coll Abbottabad 2020;32(2):263-5.

18. Kempe K, Starr B, Stafford JM, Islam A, Mooney A, Lagergren $\mathrm{E}$, et al. Results of surgical management of acute thrombembolic lower extremity ischemia. JVascSurg 2014; 60(3): 702-7.

19. Nekkanti MK, Suresh KR, Motukuru V, Kolalu S, Kabra A. Outcomes of limb and life in patients with acute lower limb schema presenting before and after the "golden six hours". Int J Adv Med 2018;5(4):788-97.

20. Ahmed MA, Karim A, Shah S, Ahmed SM. Outcome of embolectomy in patients presenting late with acute $\operatorname{limb}$ ischemia. Med Forum 2020;31(2):44-6. 